\title{
Risk assessment of vibriosis by Vibrio cholerae and Vibrio vulnificus in whip-arm octopus consumption in South Korea
}

\author{
Hyemin Oh" ${ }^{1, \#}$, Yohan Yoon ${ }^{1,2, \#, ~ J i m y e o n g ~ H a ~}{ }^{1}$, Jeeyeon Lee ${ }^{3}$, Il-Shik Shin ${ }^{4}$, Young-Mog Kim ${ }^{5}$, \\ Kwon-Sam Park ${ }^{6}$, Sejeong Kim ${ }^{1, *}$ \\ ${ }^{1}$ Risk Analysis Research Center, Sookmyung Women's University, Seoul, Korea \\ ${ }^{2}$ Department of Food and Nutrition, Sookmyung Women's University, Seoul, Korea \\ ${ }^{3}$ Department of Food and Nutrition, Dong-Eui University, Busan, Korea \\ ${ }^{4}$ Department of Marine Food Science and Technology, Gangneung-Wonju National University, Gangneoung, Korea \\ ${ }^{5}$ Department of Food Science and Technology/Institute of Food Science, Pukyong National University, Busan, Korea \\ ${ }^{6}$ Department of Food Science and Biotechnology, Kunsan National University, Gunsan, Korea
}

\begin{abstract}
This study evaluated the risk of foodborne illness from highly pathogenic Vibrio spp. (Vibrio vulnificus and V. cholerae) by raw whip-arm octopus (Octopus minor) consumption. In total 180 samples of raw whip-arm octopus were collected from markets and examined for the prevalence of $V$. vulnificus and $V$. cholerae. Predictive models describing the kinetic behavior of Vibrio spp. in raw whip-arm octopus were developed, and the data on amounts and frequency of raw whip-arm octopus consumption were collected. Using the collected data, a risk assessment simulation was conducted to estimate the probability of foodborne illness raw whip-arm octopus consumption using @RISK. Initial contamination levels of Vibrio spp. in raw whip-arm octopus were -3.9 Log colony-forming unit/g, as estimated by beta distribution fitting. The developed predictive models were appropriate to describe Vibrio spp. in raw whip-arm octopus during distribution and storage with $R^{2}$ values of $0.946-0.964$. The consumption frequency and daily consumption amounts of raw whip-arm octopus per person were $0.47 \%$ and $57.65 \mathrm{~g}$, respectively. The probability of foodborne illness from raw whip-arm octopus consumption was estimated to be $8.71 \times 10^{-15}$ for $V$. vulnificus and $7.08 \times 10^{-13}$ for $V$. cholerae. These results suggest that the risk of Vibrio spp. infection from raw whip-arm octopus consumption is low in South Korea.
\end{abstract}

Keywords: Microbial risk assessment, Highly pathogenic Vibrio spp., Raw whip-arm octopus, Vibrio vulnificus, Vibrio cholerae

Received: Mar 30, 2021 Revised: May 18, 2021 Accepted: May 23, 2021

"These authors contributed equally to this work.

${ }^{*}$ Corresponding author: Sejeong Kim

Risk Analysis Research Center, Sookmyung Women's University, Seoul, Korea

Tel: +82-2-2077-7585, Fax: +82-2-710-9479, E-mail: sjkim_11@naver.com

This is an Open Access article distributed under the terms of the Creative Commons Attribution Non-Commercial License (http://creativecommons.org/licenses/by$\mathrm{nc} / 4.0 /$ ) which permits unrestricted non-commercial use, distribution, and reproduction in any medium, provided the original work is properly cited.

Copyright $\odot 2021$ The Korean Society of Fisheries and Aquatic Science 


\section{Introduction}

Vibrio spp. are facultative, oxidase positive (except Vibrio metschnikovii), non-spore-forming gram-negative bacteria that survive in marine environments (Bross et al., 2007; Tantillo et al., 2004; Tsai et al., 2009). Pathogenic species such as Vibrio parahaemolyticus, Vibrio vulnificus, and Vibrio cholerae are causative agents of foodborne diseases upon consumption of raw or undercooked seafood (Gauthier, 2015; Yan et al., 2019). Among the pathogenic Vibrio spp., V. parahaemolyticus has been subjected to microbial risk assessment in various foods and $V$. vulnificus and $V$. cholerae are categorized as highly pathogenic Vibrio (Baker-Austin et al., 2018; Jones \& Oliver, 2009). Especially in 2020, cases of sepsis caused by $V$. vulnificus increased by two fold since 2019, and most infections were recorded between August and September (KCDC, 2020). This pathogen can cause death in approximately $50 \%$ of infected patients (KCDC, 2020). While $V$. cholerae originated abroad, domestic cases have been reported in Korea in 2016 (KCDC, 2017). V. vulnificus and V. cholerae infections may cause death in immunocompromised patients within few hours, owing to dehydration and systemic symptoms (KCDC, 2005).

The whip-arm octopus is a rich source of protein, taurine, various amino acids, iron, calcium, minerals, eicosapentaenoic acid, and docosahexaenoic acid, and its consumption decreases cholesterol levels (Lyu, 2003). Whip-arm octopus production ranks fourth among mollusks and it is the tenth most consumed seafood annually (KOSIS, 2018; KREI, 2014). In South Korea, the whip-arm octopus is occasionally consumed in the raw form. Hence, Vibrio spp. infection can be caused by whip-arm octopus consumption, owing to incomplete washing of sediment from the foreshore and storage water contaminated with Vibrio spp. V. vulnificus has been detected in whip-arm octopus (MFDS, 2003).

Therefore, this study estimated the risk of infection with highly pathogenic Vibrio spp. such as V. vulnificus and V. cholerae following whip-arm octopus consumption.

\section{Materials and Methods}

Investigation of the prevalence of highly pathogenic Vibrio spp. and collection of transfer and storage temperature/time To investigate the prevalence of highly pathogenic Vibrio spp. in whip-arm octopus, 180 whip-arm octopus samples were collected from supermarkets, wet markets, and restaurants on the south shore (Tongyeong, Korea), east shore (Gangreung, Korea), west shore (Goonsan, Korea), and central area (Seoul, Korea) of Korea. The most probable number-polymerase chain reaction (MPN-PCR) method was used to detect highly pathogenic Vibrio spp., as described by Jang et al. (2018), Kim et al. (2019), and Nandi et al. (2000). The samples (25 g) were aseptically transferred to filter bags (3M, St. Paul, MN, USA) containing $225 \mathrm{~mL}$ of $0.85 \%$ saline buffer, and the samples were pummeled using a pummeler (BagMixer ${ }^{\circledR}$, Interscience, St. Nom, France) for 1 min. Homogenates $(0.1,1$, and $10 \mathrm{~mL})$ were inoculated into five test tubes containing $10 \mathrm{~mL}$ of alkaline peptone water (APW; Oxoid, Basingstoke, UK) to obtain a final concentration of $1 \times$ APW. All tubes were incubated at $35^{\circ} \mathrm{C}$ for $14 \mathrm{~h}$. For PCR analysis, the cultures were centrifuged at $13,475 \times \mathrm{g}$ for $2 \mathrm{~min}$, and the supernatants were discarded. The cell pellets were resuspended in $0.1 \mathrm{~mL}$ of distilled water and centrifuged at $13,475 \times \mathrm{g}$ for 2 min. The suspension was heated at $100^{\circ} \mathrm{C}$ for $10 \mathrm{~min}$ to extract DNA, which was used as a DNA template for PCR (Ha et al., 2020). Primers for V. vulnificus (F: CAG CCG GAC GTC GTC CAT TTT G, R: ATG AGT AAG CGT CCG ACG CGT) and V. cholerae (F: CAC CAA GAA GGT GAC TTT ATT GTG; R: GGT TTG TCG AAT TAG CTT CAC C) were used, as suggested by Kim et al. (2015) and Nair et al. (1994), respectively. DNA amplification was performed using FastMix (Intron Bio, Seongnam, Korea), including dNTP, DNA polymerase, reaction buffer, and magnesium chloride $\left(\mathrm{MgCl}_{2}\right)$. The amplification of $V$. vulnificus and $V$. cholerae was performed as per the following procedures: initial denaturation at $94^{\circ} \mathrm{C}$ for $5 \mathrm{~min} ; 25$ cycles $(V$. vulnificus) or 30 cycles (V. cholerae) of denaturation $\left(94^{\circ} \mathrm{C}\right.$ for 30 s), elongation $\left(60^{\circ} \mathrm{C}\right.$ [V. vulnificus] or $64^{\circ} \mathrm{C}$ [V. cholerae for 30 s), and extension $\left(72{ }^{\circ} \mathrm{C}\right.$ for $\left.30 \mathrm{~s}\right)$; and final extension at $72{ }^{\circ} \mathrm{C}$ for $10 \mathrm{~min}$. PCR products were electrophoresed on a $1.5 \%$ agarose gel for $20 \mathrm{~min}$ and visualized under UV light. The number of positive test tubes per five test tubes that were analyzed by PCR was counted for each dilution, and the MPN was determined using an MPN table (FDA, 2020). A loopful of the positive test tube from the PCR analysis was streaked on thiosulfate citrate bile salts sucrose agar (TCBS; Becton, Dickinson and Company, Sparks, MD, USA), and the plates were incubated at $35^{\circ} \mathrm{C}$ for 18-24 h. The typical colonies of $V$. vulnificus and V. cholerae on the plates were inoculated into $10 \mathrm{~mL}$ tryptic soy broth (TSB, Becton, Dickinson and Company; non-selective broth) containing 3\% sodium chloride $(\mathrm{NaCl})$ to isolate a single colony and incubated at $35^{\circ} \mathrm{C}$ for $18-24 \mathrm{~h}$. Non-selective broth was used for the isolation of Vibrio spp. to improve recovery of damaged cells 
or decrease stress on Vibrio spp. The DNA extraction method, primers, and PCR conditions used were the same as those described above. The sample showing positive results in both MPN-PCR and TCBS agar was determined as positive. In addition, temperature and time during transfer and storage were collected by interviewing people who work in supermarkets, wet markets, and restaurants.

\section{Development of predictive models Preparation of inoculum}

In a previous study, the growth of $V$. vulnificus and $V$. cholerae was not different; thus, predictive models applicable to both species have been developed. Briefly, $100 \mu \mathrm{L}$ aliquots of $V$. vulnificus strains ATCC27562, NCCP14549, and NCCP11887, and V. cholerae strains NCCP14552 (non-O1) and NCCP12842 $(\mathrm{O} 23)$ in cryovials stored at $-80^{\circ} \mathrm{C}$ were inoculated into $10 \mathrm{~mL}$ of Luria-Bertani (LB) broth (Becton, Dickinson and Company) with $2 \% \mathrm{NaCl}$ and incubated at $37^{\circ} \mathrm{C}$ for $28 \mathrm{~h}$. The cultures $(0.1$ $\mathrm{mL}$ ) were then inoculated into $10 \mathrm{~mL}$ of $\mathrm{LB}$ broth plus $2 \% \mathrm{NaCl}$ and incubated at $37^{\circ} \mathrm{C}$ for $12 \mathrm{~h}$. The subcultures of $V$. vulnificus and $V$. cholerae strains were mixed and then centrifuged at $1,912 \times \mathrm{g}$ and $4{ }^{\circ} \mathrm{C}$ for $15 \mathrm{~min}$. The cell pellet was washed twice with phosphate-buffered saline (PBS; $0.2 \mathrm{~g}$ potassium chloride [ $\mathrm{KCl}$ ], $0.2 \mathrm{~g}$ monopotassium phosphate $\left[\mathrm{KH}_{2} \mathrm{PO}_{4}\right], 8.0 \mathrm{~g} \mathrm{NaCl}$, and $1.5 \mathrm{~g}$ disodium hydrogen phosphate $\left[\mathrm{Na}_{2} \mathrm{HPO}_{4} \cdot 7 \mathrm{H}_{2} \mathrm{O}\right]$ in 1 $\mathrm{L}$ distilled water $\mathrm{pH} 7.4$ ) and resuspended in $50 \mathrm{~mL}$ of APW to obtain the inoculum at $6 \mathrm{Log} \mathrm{CFU} / \mathrm{mL}$.

\section{Infecting whip-arm octopus with artificial seawater contami- nated with highly pathogenic Vibrio spp.}

If sea water is infected with $V$. vulnificus and $V$. cholerae, the pathogens can contaminate the surface and accumulate in the intestine of the octopus during breathing. Thus, a mixture of 1,750 g sun-dried salt and 1,750 g artificial sea salt (Reef Salt Mix, KENT Marine, Franklin, WI, USA) was dissolved in 100 $\mathrm{mL}$ tap water to prepare artificial seawater. To simulate the infection of the whip-arm octopus with highly pathogenic Vibrio spp. in contaminated seawater, the inoculum was inoculated into seawater at $4.0 \mathrm{Log} \mathrm{CFU} / \mathrm{mL}$ in water tanks, and the live whip-arm octopus was placed into the water tanks. Water tanks were provided with an oxygen supply device and were stored at $7{ }^{\circ} \mathrm{C}, 10^{\circ} \mathrm{C}, 15^{\circ} \mathrm{C}$, and $20^{\circ} \mathrm{C}$ for up to 6 days, depending on the storage temperature.

\section{Enumeration of highly pathogenic Vibrio spp. in octopus}

After removing the head, the whip-arm octopus was placed in the sample bag $(3 \mathrm{M})$ with twice the amount of APW. The sample was pummeled in a pummeler for $1 \mathrm{~min}$. Homogenates were diluted with APW, and the diluents were spread-plated on $\mathrm{CHROM}^{\mathrm{TM}}$ agar Vibrio (CHROMagar, Paris, France). The plates were incubated at $37^{\circ} \mathrm{C}$ for $24 \mathrm{~h}$. Typical colonies (turquoise blue) of $V$. vulnificus and V. cholerae were manually counted.

\section{Fitting cell counts of Vibrio spp. using mathematical models}

To develop a primary model, cell counts of highly pathogenic Vibrio spp. were fitted with the Baranyi model (Baranyi \& Roberts, 1994; Ha et al., 2020) using the DMfit software to calculate the maximum specific growth rate $\left(\mu_{\max } ; \mathrm{Log} \mathrm{CFU} / \mathrm{g} / \mathrm{h}\right)$ and lag phase duration $(L P D ; \mathrm{h})$ at each storage temperature. The Baranyi model is as follows:

$$
\begin{gathered}
N_{t}=N_{0}+\mu_{\max } \times \ln \left[1+\frac{\exp \left(\mu_{\max } \times A_{t}\right)-1}{\exp \left(N_{\max }-N_{0}\right)}\right] \\
A_{t}=t+\frac{1}{\mu_{\max }} \ln \left(\frac{\exp \left(-\mu_{\max }\right)+q_{0}}{1+q_{0}}\right) \\
q_{0}=\frac{1}{\exp \left(h_{0}\right)-1}
\end{gathered}
$$

The kinetic parameters were fitted into a secondary polynomial model as a function of storage temperature as follows:

$$
L P D \text { or } \mu_{\max }=a_{0}+a_{1} T^{1}+a_{2} T^{2}
$$

The performance of the developed models was evaluated by comparing the derived predicted values and objective values collected at $13^{\circ} \mathrm{C}$ and $17^{\circ} \mathrm{C}$. The differences between the predicted and observed values were indicated by the root mean square error $(R M S E)$, bias factor $\left(B_{f}\right)$, and accuracy factor $\left(A_{f}\right)$ (Ross, 1996) as follows:

$$
\begin{gathered}
\text { RMSE }=\sqrt{\sum(\text { observed value }- \text { predicted value })^{2} / n} \\
B_{f}=10^{\left.\sum \log (\text { predicted/observed }) / n\right)} \\
A_{f}=10^{\left(\sum \mid \log (\text { predicted/observed }) / n\right)}
\end{gathered}
$$

\section{Collection time and temperature for transportation and storage}

The time and temperature data for transportation and storage of the whip-arm octopus were collected via personal communication with people who were in the business. Using these data, the appropriate probability distribution for time and temperature at 
each step was determined using the @RISK program (Version 7.6, Palisade, Ithaca, NY, USA).

\section{Investigation of consumption amount and frequency}

Data on the daily consumption amount and frequency of whiparm octopuses in South Korea were obtained from the Korea National Health and Nutrition Examination Survey (2017) (KCDC, 2019). Using these data, the appropriate probability distribution for the daily consumption amount was determined using the @RISK program.

\section{Determination of the dose-response model}

To evaluate the doses (CFU) of $V$. vulnificus and $V$. cholerae that cause foodborne illness, the most appropriate dose-response models were searched and selected in the literature.

\section{Simulation to estimate risk}

A simulation model was prepared in the @RISK program with data of highly pathogenic Vibrio spp. prevalence and initial concentration, the predictive models applied to distribution time and temperature, consumption amount and frequency, and dose-response models. The risk of foodborne illnesses from highly pathogenic Vibrio spp. upon raw whip-arm octopus consumption was estimated using a simulation model with 10,000 iterations.

\section{Statistical analysis}

Kinetic parameters $\left(L P D\right.$ and $\left.\mu_{\max }\right)$ from the predictive (primary) models were analyzed using a general linear model (GLM) procedure in SAS ${ }^{\circledR}$ (Version 9.3, SAS Institute, Cary, NC, USA). The mean comparison of the kinetic parameters among storage temperatures was conducted using a pairwise $t$-test at $\alpha=0.05$.

\section{Results and Discussion}

\section{Investigation of initial V. vulnificus and $V$. cholerae contami- nation in whip-arm octopus}

To detect pathogens, we collected and examined 180 whip-arm octopus samples from supermarkets, wet markets, and restaurants of four sections, including the south shore, east shore, west shore, and central area. MPN-PCR analysis showed that V. vulnificus count was below the detection limit (30 MPN/100 g) and $V$. cholerae count was $36 \mathrm{MPN} / 100 \mathrm{~g}$ in one sample from the east shore, one sample from the west shore, and three samples from the central area. However, the cultures from contaminated samples were streaked on TCBS plates and the colonies obtained on the plates were subjected to PCR analysis, which deemed all samples negative for $V$. vulnificus and $V$. cholerae. Thus, all whip-arm octopus samples were negative for the highly pathogenic Vibrio spp., and the beta distribution fitting, as suggested by Vose (1996), estimated an initial contamination level of -3.9 Log CFU/g (Fig. 1).

\section{Probability distribution of temperature and time for trans- port and display}

Times for transport and display of whip-arm octopus were between 0 and $72 \mathrm{~h}$, and the mode was $4 \mathrm{~h}$. These values were fitted with the Pert distribution, and the result was as follows: Pert $[0,4,72]$. The collected temperatures were fitted with the minimum extreme value distribution, and the result was expressed as ExtValueMin [15.1959, 2.4783].

\section{Predictive models}

The cell counts of highly pathogenic Vibrio spp. in live whiparm octopus gradually decreased at $7{ }^{\circ} \mathrm{C}$ and $10{ }^{\circ} \mathrm{C}$ but increased at $15^{\circ} \mathrm{C}$ and $20^{\circ} \mathrm{C}$ (Fig. 2). FAO \& WHO (2020) also suggested that $V$. vulnificus failed to grow below $10{ }^{\circ} \mathrm{C}$ but could grow gradually above $15^{\circ} \mathrm{C}$. According to the previous study by Kaspar \& Tamplin (1993), the pathogenic Vibrio spp. can grow better as the temperature increases, and not survive well at temperatures below $8.5^{\circ} \mathrm{C}$, which is similar to these results. The results of our study show that Vibrio spp. can grow in live seafood during storage at temperatures above $15^{\circ} \mathrm{C}$. The fitting results from the Baranyi model with the cell counts produced kinetic parameters such as $L P D$ and $\mu_{\max }$, as shown in Table 1. Since the Baranyi model provides biological interpretation for the duration of the lag phase, and both growth and death rates, the model was used for primary modeling. The $R^{2}$ values were 0.694-0.930. The $L P D$ decreased but increased as the temperature increased (Table 1). The LPD and $\mu_{\max }$ values were fitted with a polynomial model as a function of temperature, and the secondary models are presented in Table 2 . The $R^{2}$ values of the secondary models were 0.946 and 0.964 for $L P D$ and $\mu_{\max }$, respectively (Table 2). Thus, the developed secondary models were appropriate to describe the effect of temperature on the kinetic parameters (Fig. 3). The validation results showed that RMSEs were 0.307 and 0.263 at $13^{\circ} \mathrm{C}$ and $17^{\circ} \mathrm{C}$, respectively. As $R M S E$ approaches 0 , the prediction of the secondary predictive model is accurate. Furthermore, $B_{f}$ values were 1.02 and 0.96 at $13{ }^{\circ} \mathrm{C}$ and $17^{\circ} \mathrm{C}$, respectively, indicating that the predictive models 
(A)

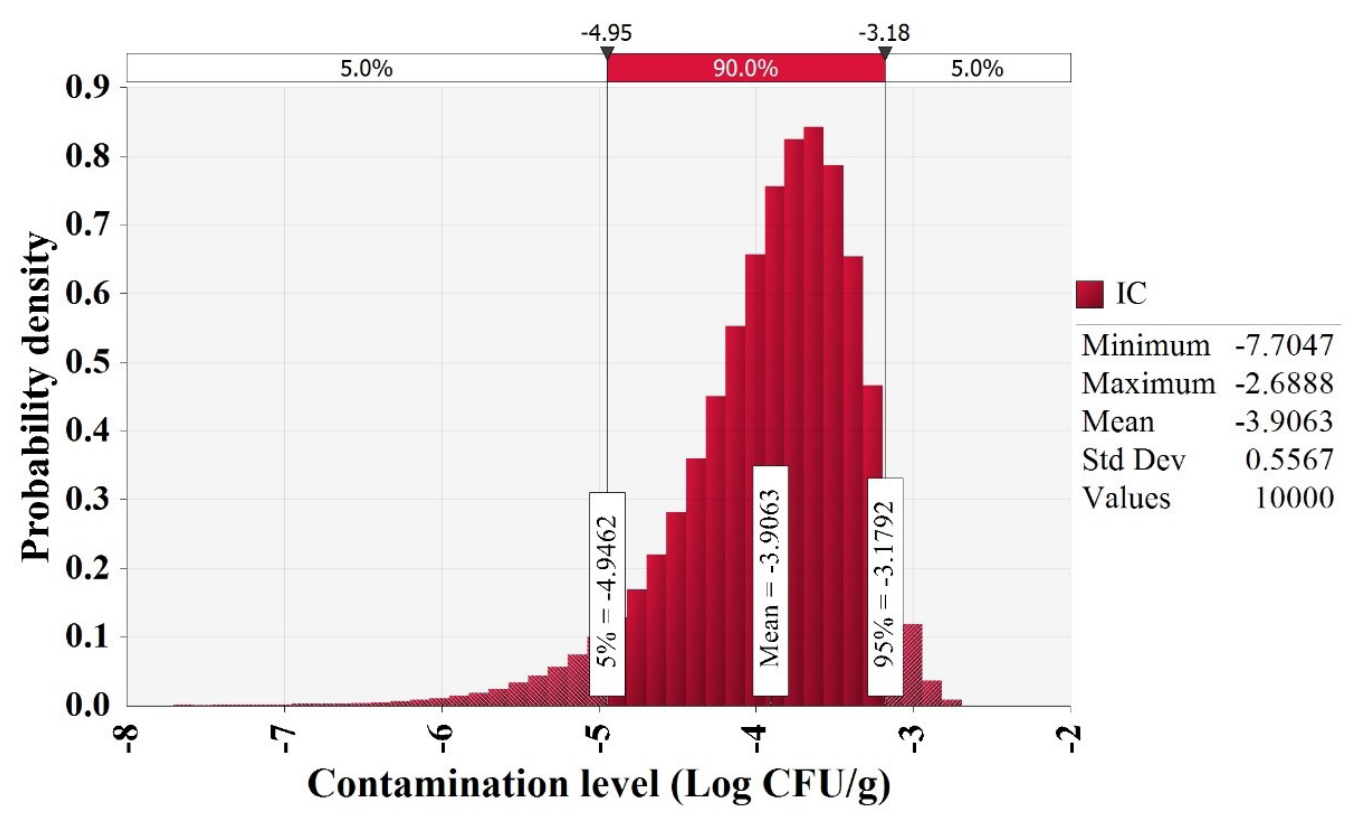

(B)

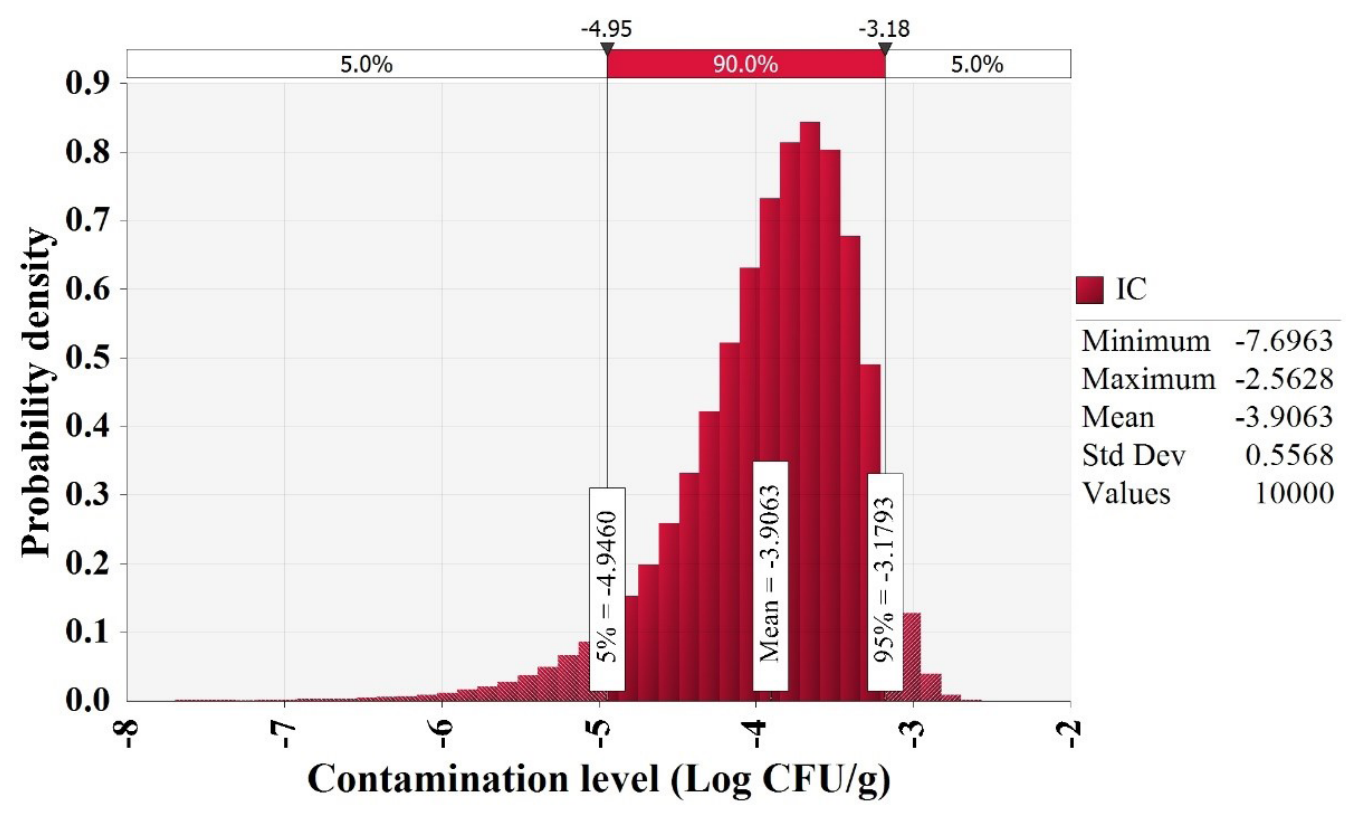

Fig. 1. Probable distributions for initial contamination levels of Vibrio vulnificus (A) and Vibrio cholerae (B) in raw whip-arm octopus.

over-predict by $2 \%$ at $13^{\circ} \mathrm{C}$ and under-predict by $4 \%$ at $17^{\circ} \mathrm{C}$. $A_{f}$ values were 1.06 and 1.05 at $13^{\circ} \mathrm{C}$ and $17^{\circ} \mathrm{C}$, respectively. As $A_{f}$ value approaches 1 , the prediction of the predictive model is accurate. Although $R^{2}$ values were not very high in the primary models, the validation results indicate that the developed predictive models were appropriate to describe cell count changes of highly pathogenic Vibrio spp. under the temperature and time during transport and display of live whip-arm octopus. 
(A)

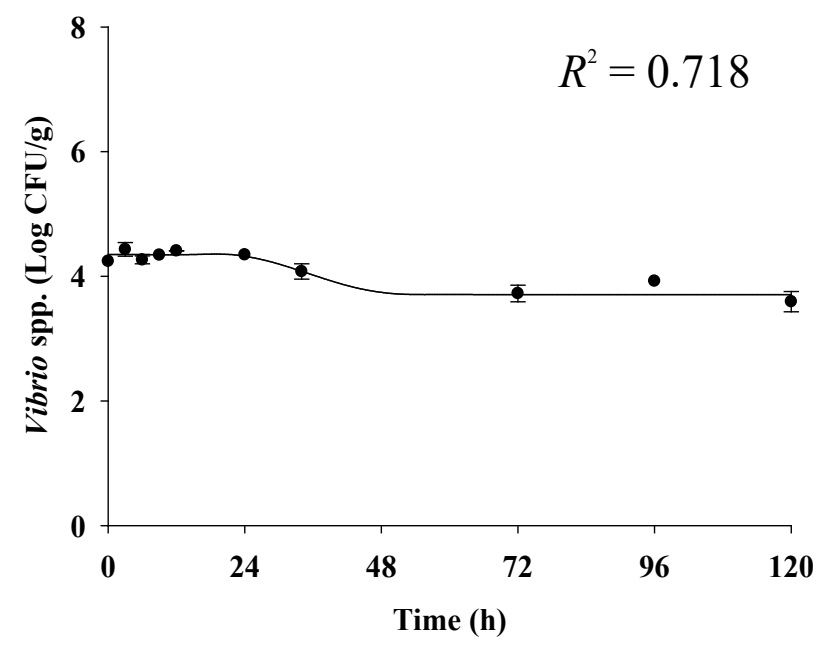

(C)

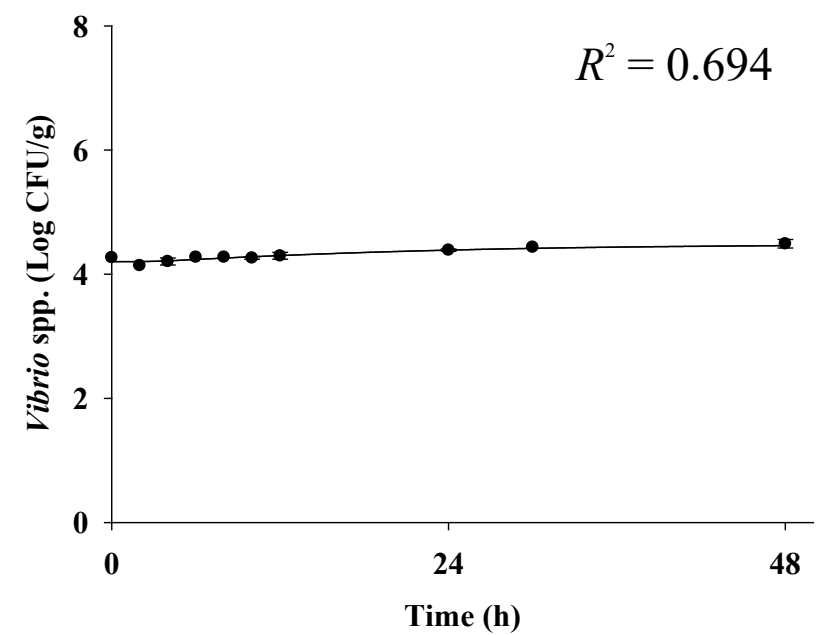

(B)

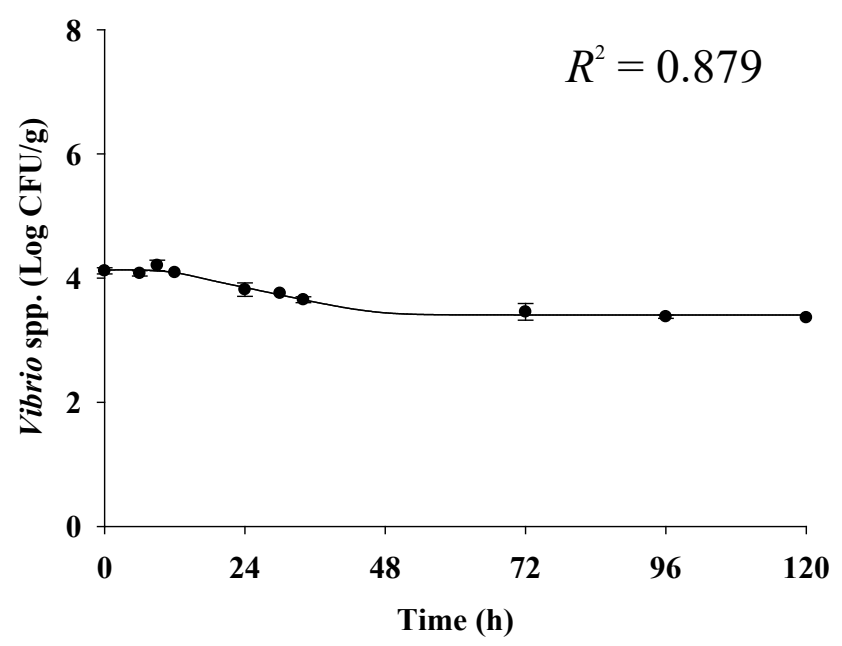

(D)

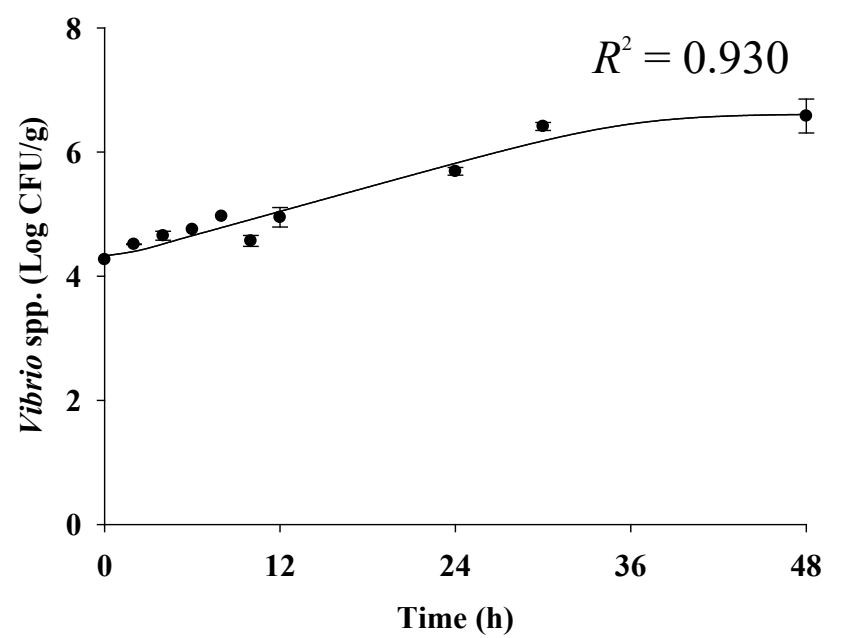

Fig. 2. Results of primary modeling for highly pathogenic Vibrio spp. growth in raw whip-arm octopus during storage at $7^{\circ} \mathrm{C}$ (A), $10^{\circ} \mathrm{C}(\mathrm{B}), 15^{\circ} \mathrm{C}(\mathrm{C})$, and $20^{\circ} \mathrm{C}(\mathrm{D})(\cdot$, observed data; - , fitted line).

Table 1. Kinetic parameters calculated by primary model for pathogenic Vibrio spp. in raw whip-arm octopus

\begin{tabular}{lllll}
\hline Kinetic parameters & \multicolumn{5}{l}{ Temperature $\left({ }^{\circ} \mathrm{C}\right)$} & 15 & 20 \\
\cline { 2 - 5 } & 4 & 10 & $0.02 \pm 0.00$ & $0.05 \pm 0.01$ \\
\hline$\mu_{\max }$ & $-0.03 \pm 0.01$ & $-0.02 \pm 0.00$ & $3.35 \pm 0.23$ & $0.98 \pm 0.08$ \\
$R^{2}$ & $22.93 \pm 2.35$ & $8.69 \pm 1.81$ & $0.694 \pm 0.080$ & $0.930 \pm 0.018$ \\
\hline
\end{tabular}

$\mu_{\text {max }}$ maximum specific growth rate (Log CFU/g/h), indicating death and growth rates; LPD, lag phase duration (h), period of no cell count change in a growth/death curve. 
Table 2. Equations of secondary model for predicting $\mu_{\max }$ and LPD of pathogenic Vibrio spp. in raw whip-arm octopus

\begin{tabular}{lll}
\hline Parameter & Equation & $R^{2}$ \\
\hline$\mu_{\max }$ & $\mu_{\max }=-0.0875+0.007 \times T$ & 0.964 \\
$L P D$ & $L P D=60.0506-6.8472 \times T+0.1961 \times T^{2}$ & 0.946 \\
\hline
\end{tabular}

$T$, temperature $\left({ }^{\circ} \mathrm{C}\right) ; \mu_{\max }$ maximum specific growth rate (Log CFU/g/h); $L P D$, lag phase duration (h).

(A)

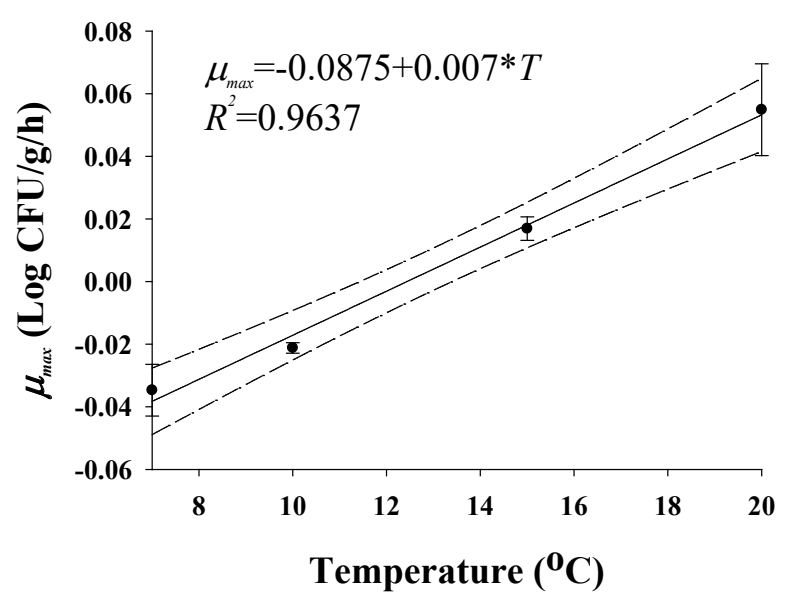

(B)

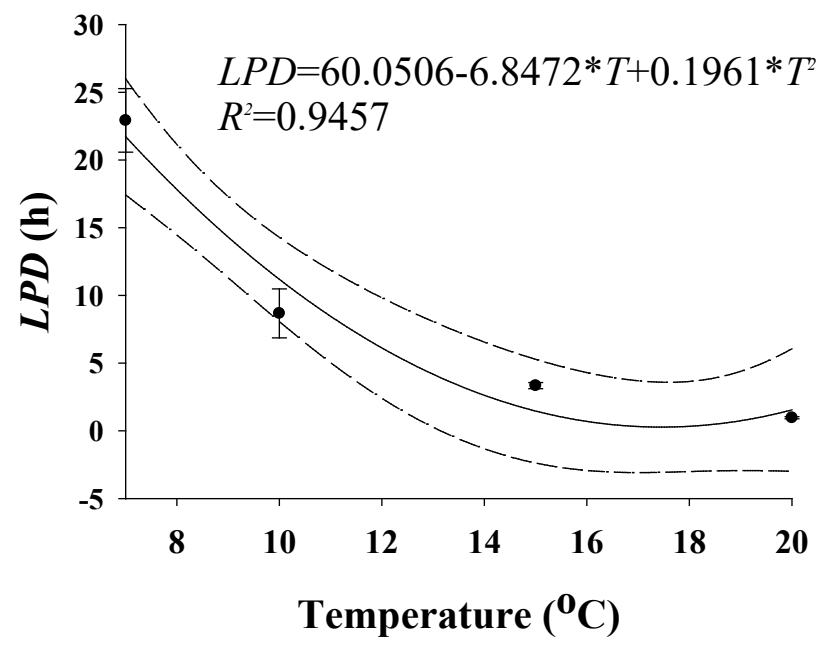

Fig. 3. Results of secondary modeling for $\mu_{\max }$ (maximum specific growth rate) (A) and LPD (lag phase duration) (B) of highly pathogenic Vibrio spp. in raw whip-arm octopus as a function of temperature (०, observed data; - , fitted line; ---, 95\% confidence interval).

\section{Consumption amount and frequency}

In Korea National Health and Nutrition Examination Survey (KCDC, 2019), 34 of 7,167 respondents had consumed whiparm octopus, and the consumption frequency was $0.47 \%$ $[(34 / 7,167) \times 100]$. Hence, the discrete distribution was used to describe the probability of consuming a whip-arm octopus. The consumption amounts from the respondents with whip-arm octopus were fitted with @RISK. The appropriate probability distribution was the exponential distribution (Expon [55.585, Shift [3.0651]) that showed an average consumption of $58.65 \mathrm{~g}$ (Fig. 4).

\section{Dose response models}

To estimate the dose responses of $V$. vulnificus and $V$. cholerae, the commonly used Beta-Poisson model (probability $=1-[1+$ dose $\left./ \beta]^{-a}\right)$ was selected. For $V$. vulnificus, the parameters were $\alpha=9.3 \times 10^{-6}$ and $\beta=1.1 \times 10^{5}$ (WHO \& FAO, 2005a). For $V$. cholerae, the parameters were $\alpha=1.31 \times 10^{-1}$ and $\beta=1.49 \times 10^{7}$ (Cash et al., 1974; WHO \& FAO, 2005b).

\section{Risk characterization}

The simulation models were formulated with the estimated levels of initial contamination, predictive models, probability distributions for temperature and time, probability distribution of consumption amounts, consumption frequency, and dose response models, as presented in Table 3. The simulation showed that the contamination levels of $V$. vulnificus and $V$. cholerae in whip-arm octopus samples were $-3.8 \mathrm{Log} \mathrm{CFU} / \mathrm{g}$ after transport and display (Fig. 5), indicating only $0.1 \mathrm{Log}$ CFU/ $\mathrm{g}$ increase from the initial contamination level (-3.9 Log CFU/ g). Thus, the highly pathogenic Vibrio spp. do not grow in live whip-arm octopus at the investigated temperature and time. Live whip-arm octopus was transported and displayed at $0^{\circ} \mathrm{C}-$ $10^{\circ} \mathrm{C}$ and sold within 4 days. Therefore, the pathogen could not 


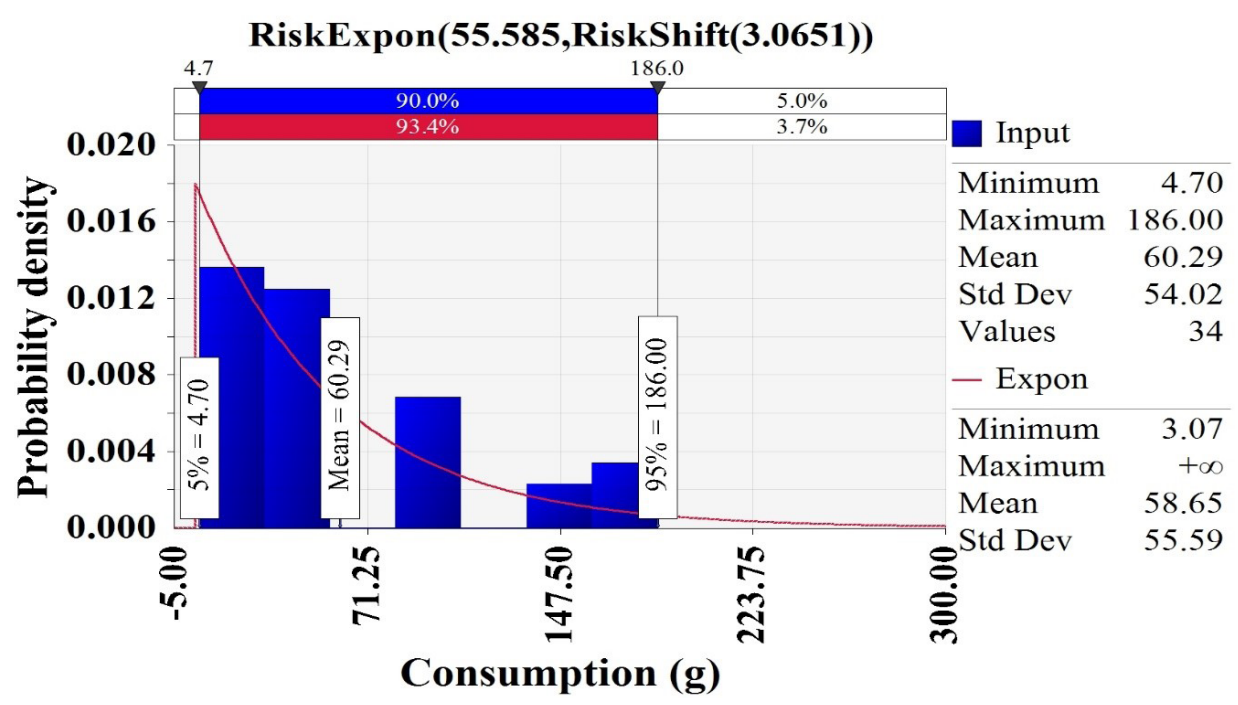

Fig. 4. Probabilistic distribution for raw whip-arm octopus consumption obtained from the Korea National Health and Nutrition Examination Survey (KNHNES) fitted by @RISK.

Table 3. Excel spreadsheet for calculating the risk of Vibrio spp. in raw whip-arm octopus with @RISK

\begin{tabular}{|c|c|c|c|c|}
\hline Input model & Unit & Variable & Formula & Reference \\
\hline \multicolumn{5}{|l|}{ DISTRIBUTION } \\
\hline \multicolumn{5}{|l|}{ Product } \\
\hline \multicolumn{5}{|l|}{ Pathogens contamination level } \\
\hline V. vulnificus prevalence & & PR & $=$ RiskBeta $(1,181)$ & This research; Vose (1996) \\
\hline V. cholerae prevalence & & PR & $=$ RiskBeta $(1,181)$ & \\
\hline \multirow[t]{2}{*}{ Initial contamination level } & $\mathrm{CFU} / \mathrm{g}$ & $\mathrm{C}$ & $=-\ln (1-P R) / 25$ & Sanaa et al. (2004) \\
\hline & $\log \mathrm{CFU} / \mathrm{g}$ & IC & $=\log (C)$ & \\
\hline \multicolumn{5}{|l|}{ MARKET } \\
\hline \multicolumn{5}{|l|}{ Market display } \\
\hline Display time & $\mathrm{h}$ & Time $_{\text {mark-dis }}$ & $=$ RiskPert $(0,4,72)$ & This research; Personal communication" \\
\hline Display temperature & ${ }^{\circ} \mathrm{C}$ & Temp $_{\text {mark-dis }}$ & $\begin{aligned}= & \text { RiskExtValueMin }(15.1959,2.4783, \\
& \text { RiskTruncate }(0,18.8))\end{aligned}$ & This research; Personal communication \\
\hline \multicolumn{5}{|l|}{ Growth/death } \\
\hline & $\log \mathrm{CFU} / \mathrm{g}$ & $h_{0}$ & $=$ Average $\left(\mu_{\max } \times L P D\right)$, Fixed 0.02767 & This research; Baranyi \& Roberts (1994) \\
\hline & $\log \mathrm{CFU} / \mathrm{g}$ & $Y_{0}$ & $=$ Average $\left(\mathrm{Y}_{0 i}\right)$, Fixed 4.3 & This research; Baranyi \& Roberts (1994) \\
\hline & $\log \mathrm{CFU} / \mathrm{g}$ & $Y_{\text {end }}$ & $=$ Average $\left(\mathrm{Y}_{\text {endi }}\right)$, Fixed 4.6 & This research; Baranyi \& Roberts (1994) \\
\hline & & $\ln (q)$ & $=\ln \left(1 /\left(\operatorname{EXP}\left(h_{0}\right)-1\right)\right)$ & This research; Baranyi \& Roberts (1994) \\
\hline$\mu_{\max }$ & $\log \mathrm{CFU} / \mathrm{g} / \mathrm{h}$ & $\mathrm{GR}_{\text {mark-dis }}$ & $=-0.0875+0.007 \times$ Temp $_{\text {mark-dis }}$ & This research; Baranyi \& Roberts (1994) \\
\hline $\begin{array}{l}\text { Pathogenic Vibrio growth/death } \\
\text { model }\end{array}$ & $\log \mathrm{CFU} / \mathrm{g}$ & $\mathrm{C} 1$ & $\begin{aligned}= & \mathrm{IC}+1 /(1+\operatorname{EXP}(-\operatorname{In}(\mathrm{q}))) \times\left(1-10^{-\mid \mathrm{Y} 0 \text {-Yendl }} /\right. \\
& \ln (10)) \times \mathrm{GR}_{\text {mark-dis }} \times \text { Time }_{\text {mark-dis }}\end{aligned}$ & This research; Baranyi \& Roberts (1994) \\
\hline \multicolumn{5}{|l|}{ CONSUMPTION } \\
\hline \multirow[t]{4}{*}{ Daily consumption frequency } & $\%$ & ConFre & Fixed 0.47 & KCDC (2019) \\
\hline & & $\mathrm{CF}(0)$ & $=1-0.47 / 100$ & KCDC (2019) \\
\hline & & $\mathrm{CF}(1)$ & $=0.47 / 100$ & KCDC (2019) \\
\hline & & $\mathrm{CF}$ & $=$ RiskDiscrete $(\{0,1\},\{C F(0), C F(1)\})$ & KCDC (2019) \\
\hline Daily consumption amount & $\mathrm{g}$ & Consump & $\begin{aligned}= & \text { RiskExpon }(55.585, \text { RiskShift }(3.0651), \\
& \text { RiskTruncate }(4,190))\end{aligned}$ & KCDC (2019) \\
\hline
\end{tabular}


Table 3. Continued

\begin{tabular}{|c|c|c|c|c|}
\hline Input model & Unit & Variable & Formula & Reference \\
\hline Final consumption amount & $g$ & Amount & $=\mathrm{IF}(\mathrm{CF}=0,0$, Consump $)$ & \\
\hline \multicolumn{5}{|l|}{ DOSE-RESPONSE } \\
\hline \multirow[t]{3}{*}{ V.vulnificus amount } & CFU & $\mathrm{D}$ & $=10^{\mathrm{C} 1} \times$ Amount & \\
\hline & & $a$ & Fixed $9.3 \times 10^{-6}$ & WHO \& FAO (2005a) \\
\hline & & $\beta$ & Fixed $1.1 \times 10^{5}$ & WHO \& FAO (2005a) \\
\hline \multirow[t]{3}{*}{ V. cholerae amount } & CFU & $\mathrm{D}$ & $=10^{C 1} \times$ Amount & \\
\hline & & $a$ & Fixed $1.31 \times 10^{-1}$ & Cash et al. (1974); WHO \& FAO (2005b) \\
\hline & & $\beta$ & Fixed $1.49 \times 10^{7}$ & Cash et al. (1974); WHO \& FAO (2005b) \\
\hline \multicolumn{5}{|l|}{ RISK } \\
\hline Probability of illness/person/day & & Risk & $=1-(1+D / \beta)^{-a}$ & $\begin{array}{l}\text { Cash et al. (1974); WHO \& FAO (2005a, } \\
\text { 2005b) }\end{array}$ \\
\hline
\end{tabular}

1) Personal communication with experts.

(A)

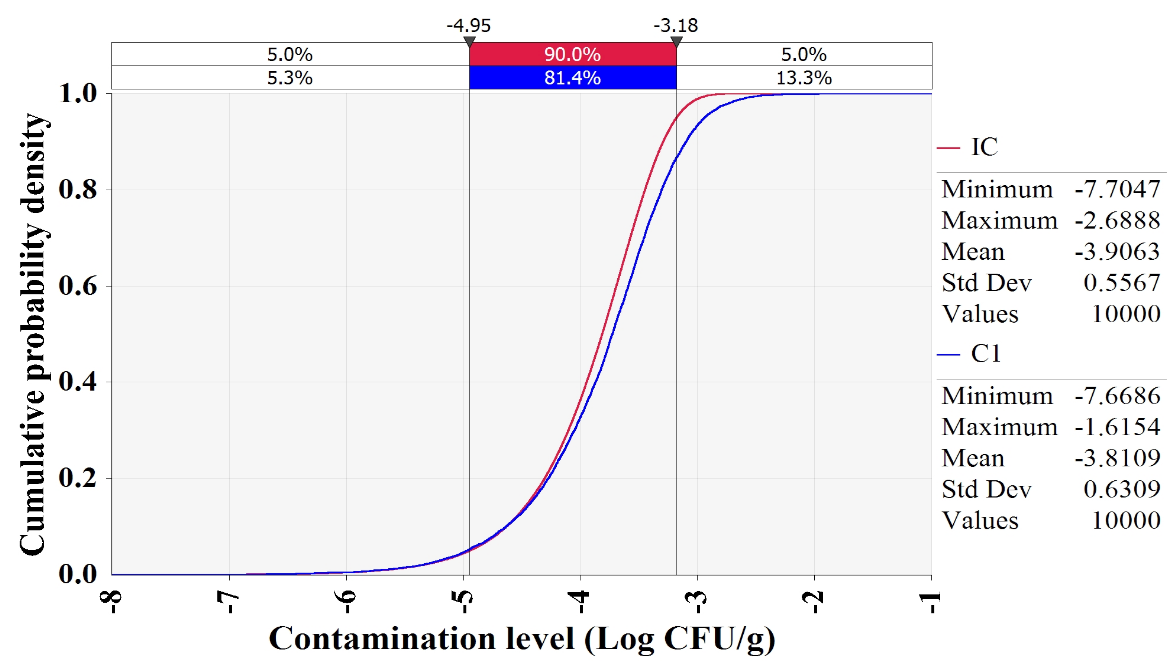

(B)

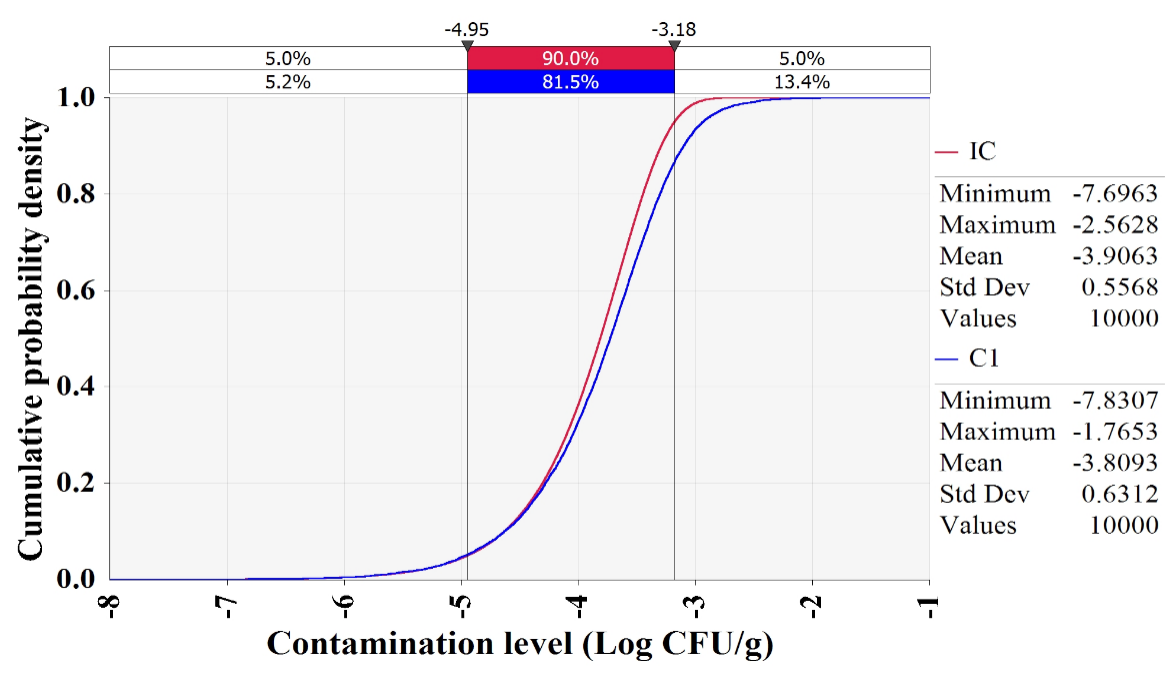

Fig. 5. Growth of Vibrio spp. in raw whip-arm octopus during domestic distribution (IC, initial concentration; C1, concentration after display at markets). 
(A)

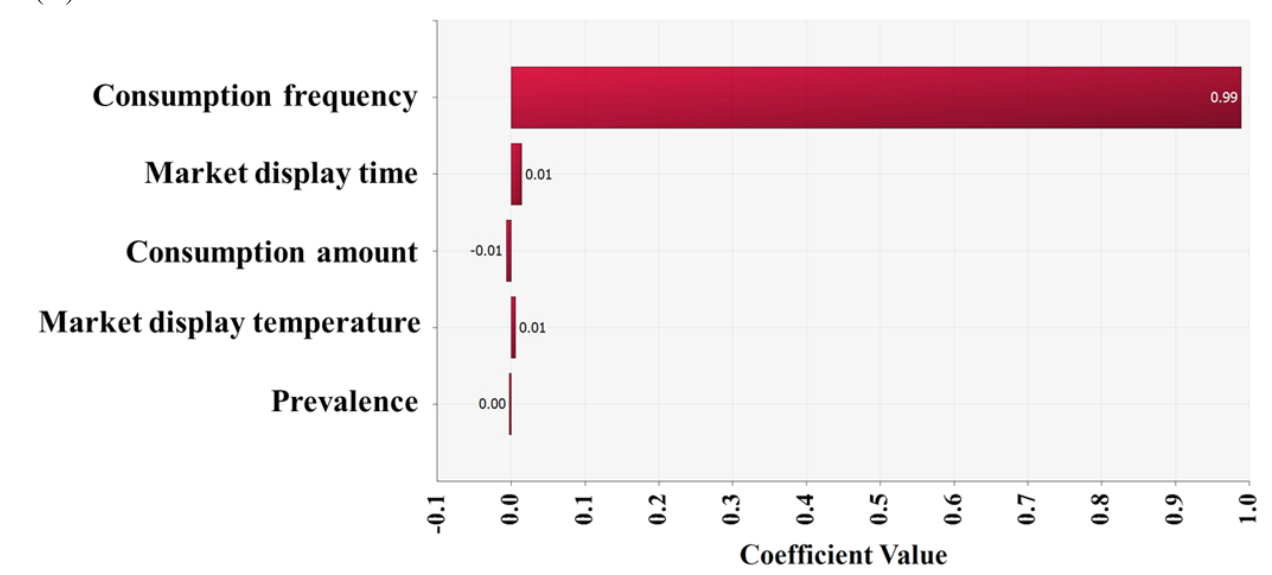

(B)

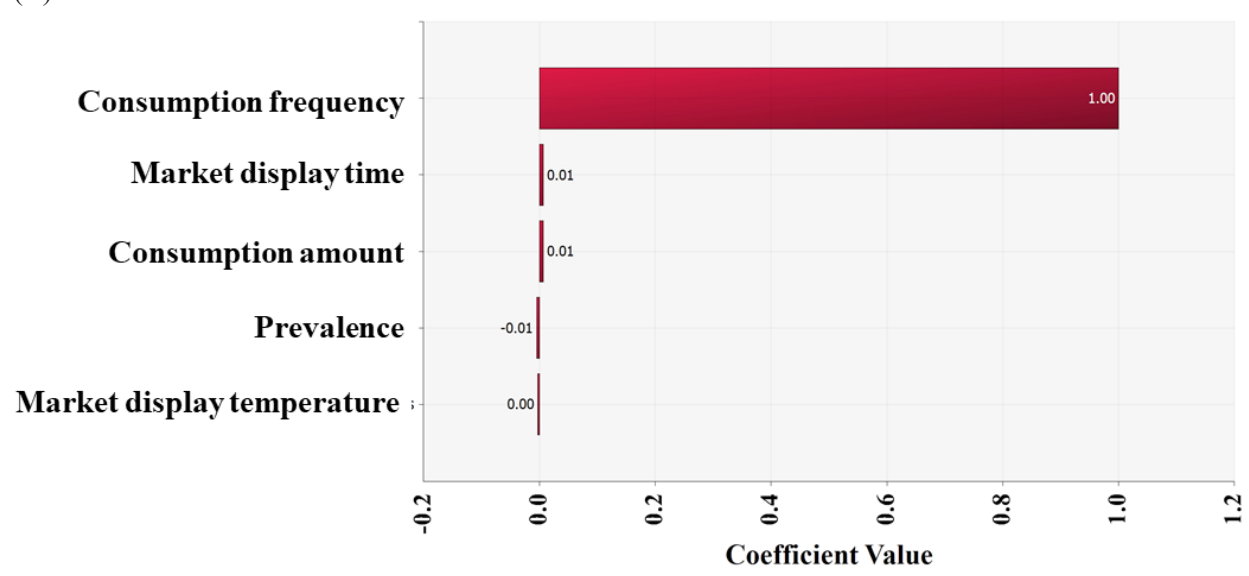

Fig. 6. Correlation coefficient values of risk factors, affecting the probability of foodborne illness caused by Vibrio spp. per person per day following raw whip-arm octopus consumption.

grow. In addition, the simulation showed that the probabilities of foodborne illness per person per day were $8.71 \times 10^{-15}$ for $V$. vulnificus and $7.08 \times 10^{-13}$ for V. cholerae.

In conclusion, the risk of infection by the highly pathogenic Vibrio spp. via raw whip-arm octopus consumption is low. This might be related to the low contamination level and low growth of pathogens under the conditions of temperature and time. In addition, a very low consumption frequency (0.47\%) affected the risk, as indicated by the correlation coefficient (Fig. 6).

\section{Competing interests}

No potential conflict of interest relevant to this article was reported.

\section{Funding sources}

This research was supported by a grant (18162MFDS542) from the Ministry of Food and Drug Safety in 2019.

\section{Acknowledgements}

Not applicable.

\section{Availability of data and materials}

Upon reasonable request, the datasets of this study can be available from the corresponding author.

\section{Ethics approval and consent to participate}

This article does not require IRB/IACUC approval because there are no human and animal participants. 


\section{ORCID}

Hyemin Oh

Yohan Yoon

Jimyeong Ha

Jeeyeon Lee

Il-Shik Shin

Young-Mog Kim

Kwon-Sam Park

Sejeong Kim https://orcid.org/0000-0002-8073-7242

https://orcid.org/0000-0002-4561-6218

https://orcid.org/0000-0001-7973-7926

https://orcid.org/0000-0002-5885-6835

https://orcid.org/0000-0003-1145-5230

https://orcid.org/0000-0002-2465-8013

https://orcid.org/0000-0003-2298-1981

https://orcid.org/0000-0001-9741-8056

\section{References}

Baker-Austin C, Oliver JD, Alam M, Ali A, Waldor MK, Qadri F, et al. Vibrio spp. infections. Nat Rev Dis Primers. 2018;4:119.

Baranyi J, Roberts TA. A dynamic approach to predicting bacterial growth in food. Int J Food Microbiol. 1994; 23:277-94.

Bross MH, Soch K, Morales R, Mitchell RB. Vibrio vulnificus infection: diagnosis and treatment. Am Fam Physician. 2007;76:539-44.

Cash RA, Music SI, Libonati JP, Snyder MJ, Wenzel RP, Hornick RB. Response of man to infection with Vibrio cholerae. I. Clinical, serologic, and bacteriologic responses to a known inoculum. J Infect Dis. 1974;129:45-52.

Food and Agriculture Organization of the United Nations [FAO], World Health Organization [WHO]. Risk assessment tools for Vibrio parahaemolyticus and Vibrio vulnificus associated with seafood. Rome: FAO; 2020.

Food and Drug Administration of the United Nations [FDA]. BAM appendix 2: most probable number from serial dilutions 2020. [Internet]. 2020 [cited 2021 Jan 6]. https:// www.fda.gov/food/laboratory-methods-food/bam-appendix-2-most-probable-number-serial-dilutions

Ha J, Lee J, Oh H, Kim HJ, Choi Y, Lee Y, et al. Description of kinetic behavior of pathogenic Escherichia coli in cooked pig trotters under dynamic storage conditions using mathematical equations. Food Sci Anim Resour. 2020;40:938-45.

Ha J, Lee J, Oh H, Shin IS, Kim YM, Park KS, et al. Microbial risk assessment of high risk Vibrio foodborne illness through raw oyster consumption. J Food Hyg Saf. 2020;35:37-44.

Gauthier DT. Bacterial zoonoses of fishes: a review and appraisal of evidence for linkages between fish and human infections. Vet J. 2015;203:27-35.

Jang YM, Park SK, Jeong HJ, Lee JW, Yoon YH, Park KS, et al.

Quantitative cell count of Vibrio vulnificus cells based on MPN-PCR method. J Food Hyg Saf. 2018;33:412-5.

Jones MK, Oliver JD. Vibrio vulnificus: disease and pathogenesis. Infect Immun. 2009;77:1723-33.

Kaspar CA, Tamplin ML. Effects of temperature and salinity on the survival of Vibrio vulnificus in seawater and shellfish. Appl Environ Microbiol. 1993;59:2425-9.

Kim HJ, Ryu JO, Lee SY, Kim ES, Kim HY. Multiplex PCR for detection of the Vibrio genus and five pathogenic Vibrio species with primer sets designed using comparative genomics. BMC Microbiol. 2015;15:239.

Kim JU, Park JH, Kang HS. Changing consumer intake of oyster, a twenties focus group study. J Fish Mar Sci Educ. 2019;31:1150-60.

Korea Centers for Disease Control and Prevention [KCDC]. Vibrio management guidelines. [Internet]. 2005 [cited 2020 Dec 20]. https://kdca.go.kr/board/board.es?mid=a2050702 0000\&bid $=0019 \&$ act $=$ view\&list_no $=138508$

Korea Centers for Disease Control and Prevention [KCDC]. Epidemiological investigation of infectious diseases in Korea, Annual report 2016. [Internet] 2017 [cited 2021 Jan 5]. http://www.kdca.go.kr/npt/biz/npp/portal/nppPblctDtaView.do?pblctDtaSeAt $=5 \&$ pblctDtaSn $=23$

Korea Center for Disease Control and Prevention, [KCDC]. National health statistics in 2017. [Internet]. 2019 [cited 2021 Jan 10]. https://knhanes.kdca.go.kr/knhanes/main.do

Korea Centers for Disease Control and Prevention [KCDC]. Increasing incidence of patients with Vibrio sepsis 328 [Internet]. 2020 [cited 2021 Jan 5]. https://kdca.go.kr/board/ board.es? $\mathrm{mid}=\mathrm{a} 20501010000 \& \mathrm{bid}=0015 \&$ act $=$ view\&list no $=364775$

Korea Rural Economic Institute [KREI]. Food balance sheet. Naju, Korea: KREI; 2014.

Korean Statistical Information Service [KOSIS]. Fishery production trend survey 2018 [Internet]. 2018 [cited 2021 Jan 2]. https://kosis.kr/statHtml/statHtml.do?orgId=101\&tblid=DT_1EW0001

Lyu ES. The standardized recipe and nutrient analysis of stirfried whip-arm octopus in Busan. J Korean Soc Food Cult. 2003;18:9-16.

Ministry of Food and Drug Safety [MFDS]. Numbers and toxicities of Vibrio vulnificus in various natural samples. 2003.

Nair GB, Ramamurthy T, Bhattacharya SK, Mukhopadhyay AK, Garg S, Bhattacharya MK, et al. Spread of Vibrio cholerae O139 Bengal in India. J Infect Dis. 1994;169:1029-34. 
Nandi B, Nandy RK, Mukhopadhyay S, Nair GB, Shimada T, Ghose AC. Rapid method for species-specific identification of Vibrio cholerae using primers targeted to the gene of outer membrane protein OmpW. J Clin Microbiol. 2000;38:4145-51.

Ross T. Indices for performance evaluation of predictive models in food microbiology. J Appl Bacteriol. 1996;81:501-8.

Sanaa M, Coroller L, Cerf O. Risk assessment of listeriosis linked to the consumption of two soft cheeses made from raw milk: Camembert of Normandy and Brie of Meaux. Risk Anal. 2004;24:389-99.

Tantillo GM, Fontanarosa M, Di Pinto A, Musti M. Updated perspectives on emerging Vibrios associated with human infections. Lett Appl Microbiol. 2004;39:117-26.

Tsai YH, Huang TJ, Hsu RWW, Weng YJ, Hsu WH, Huang KC, et al. Necrotizing soft-tissue infections and primary sepsis caused by Vibrio vulnificus and Vibrio cholerae non-O1. J Trauma. 2009;66:899-905.

Vose D. Quantitative risk analysis: a guide to Monte Carlo simulation modelling. Chichester, New York, NY: John \& Wiley Sons; 1996.

World Health Organization [WHO], Food and Agriculture Organization of the United Nations [FAO]. Risk assessment of Vibrio vulnificus in raw oysters: interpretative summary and technical report. Rome: FAO; 2005a.

World Health Organization [WHO], Food and Agriculture Organization of the United Nations [FAO]. Risk assessment of choleragenic Vibrio cholerae $\mathrm{O} 1$ and $\mathrm{O} 139$ in warm water shrimp in international trade: interpretative summary and technical report. Rome: FAO; 2005b.

Yan L, Pei X, Zhang X, Guan W, Chui H, Jia H, et al. Occurrence of four pathogenic Vibrios in Chinese freshwater fish farms in 2016. Food Control. 2019;95:85-9. 